\title{
A high proportion of SARS- CoV-2-infected university students are asymptomatic
}

The estimated percentage of asymptomatic students infected with SARS-CoV-2 ranged from $73 \%$ to $92.5 \%$ by week and was $81.1 \%$ overall.
$\mathrm{M}$ any individuals infected with SARS-CoV-2 never become symptomatic. In a South Korean study, these infected individuals remained asymptomatic for a prolonged period while maintaining the same viral load as symptomatic patients, suggesting that they are just as infectious. ${ }^{1}$ A narrative review found high rates of asymptomatic disease in several younger populations, including women in an obstetric ward (88\%), the crew of an aircraft carrier (58\%), and prisoners (96\%). ${ }^{2}$ However, there is no published research on the percentage of university students who are asymptomatic.

\section{Methods}

The University of Georgia (UGA) began classes on August 20, 2020. Shortly before the beginning of classes, UGA implemented a surveillance program for asymptomatic students, faculty, and staff, testing 300 to 450 people per day. Initially, during Weeks 1 and 2 of data collection, anyone could choose to be tested. In Weeks 3 and 4, students, faculty, and staff were randomly invited to participate.

Over the 4-week period beginning on August 17, we calculated the percent of positive cases in surveillance testing and applied this percentage to the entire UGA student population ( $\mathrm{n}=38,920)$ to estimate the total number of asymptomatic COVID-19 students each week. ${ }^{3}$ Data for symptomatic cases were also reported by the university on a weekly basis. This included positive tests from the University Health Center, as well as voluntary reporting using a smartphone app from other sites.

Positive tests in symptomatic individuals were not stratified by student vs nonstudent until Week 3 ; students comprised $95 \%$ of positive symptomatic reports in Week 3 and
$99 \%$ in Week 4 , so we conservatively estimated that $95 \%$ of symptomatic cases in Weeks 1 and 2 were students. These data were used to estimate the percentage of SARS-CoV-2positive students who were asymptomatic.

\section{Results}

Our results are summarized in the tABLE. The percentage of asymptomatic students testing positive in surveillance testing was $3.4 \%$ in Week 1 and rose steadily to $9 \%$ by Week 4 . We estimated that there were 1303 asymptomatic cases among students in Week 1, increasing to 3487 asymptomatic positive students on campus by Week 4 . The estimated percentage of asymptomatic students infected with SARS-CoV-2 ranged from $73 \%$ to $92.5 \%$ by week and was $81.1 \%$ overall.

\section{Discussion}

During the reporting period from August 17 to September 13, the 7-day moving average of new cases in Clarke County (home of UGA) increased from 30 to 83 per 100,000 persons/ day (https://dph.georgia.gov/covid-19-dailystatus-report). During this period, there were large increases in the number of infected students, more than $80 \%$ of whom were asymptomatic. With the assumption that anyone could be infected even if asymptomatic, these numbers highlight the importance for infection control to prevent potential spread within a community by taking universal precautions such as wearing a mask, following physical distancing guidelines, and handwashing.

I Limitations. First, reporting of positive tests in symptomatic individuals is highly encouraged but not required. The large drop in symptomatic positive test reports between Weeks 3 and 4, with no change in test positiv- 
TABLE

\section{SARS-CoV-2 infection: Symptomatic student cases and surveillance of asymptomatic students at the University of Georgia}

\begin{tabular}{l|l|l|l|l}
\hline $\begin{array}{l}\text { Week: Dates of } \\
\text { data collection }\end{array}$ & $\begin{array}{l}\text { Reported } \\
\text { symptomatic cases } \\
\text { among students }\end{array}$ & $\begin{array}{l}\text { Positive cases/total }(\% ; 95 \% \\
\text { Cl) in surveillance testing of } \\
\text { asymptomatic students }\end{array}$ & $\begin{array}{l}\text { Estimated asymptomatic } \\
\text { positive cases in full student } \\
\text { population }(95 \% \mathrm{Cl})^{\mathrm{a}}\end{array}$ & $\begin{array}{l}\text { Asymptomatic/ } \\
\text { total cases }(\%)^{\mathrm{b}}\end{array}$ \\
\hline $\mathbf{1 :} 8 / 17$ to $8 / 23$ & $149 \mathrm{c}$ & $\mathbf{2 9 / 8 6 6 ( 3 . 4 \% ; 2 . 3 \% - 4 . 8 \% )}$ & $1303(876-1856)$ & $1303 / 1452(89.7 \%)$ \\
\hline 2: $8 / 24$ to $8 / 30$ & $783^{c}$ & $95 / 1539(6.2 \% ; 5 \%-7.4 \%)$ & $2402(1935-2870)$ & $2402 / 3185(75.4 \%)$ \\
\hline 3: $8 / 31$ to $9 / 6$ & 1277 & $\begin{array}{l}125 / 1407(8.9 \% ; 7.4 \%- \\
10.4 \%)\end{array}$ & $3458(2879-4036)$ & $3458 / 4735(73 \%)$ \\
\hline 4: $9 / 7$ to $9 / 13$ & 281 & $123 / 1373(9 \% ; 7.5 \%-10.5 \%)$ & $3487(2899-4075)$ & $3487 / 3768(92.5 \%)$ \\
\hline All periods & & & & $\mathbf{1 0 , 6 5 0 / 1 3 , 1 4 0 ( 8 1 . 1 \% )}$ \\
\hline
\end{tabular}

$\mathrm{Cl}$, confidence interval.

${ }^{a}$ Estimates from surveillance testing are based on student population of $38,920 .^{3}$

${ }^{b}$ Total cases is the sum of reported symptomatic cases among students (column 2) plus the estimated asymptomatic positives in the full student population (column 4).

' This is adjusted based on the assumption that $95 \%$ of all reported symptomatic positive tests were in students, based on Week 3 data.

ity in surveillance of asymptomatic students ( $8.9 \%$ vs $9 \%$ ), suggests that students may have chosen to be tested elsewhere in conjunction with evaluation of their symptoms and/or not reported positive tests, possibly to avoid mandatory isolation and other restrictions on their activities. Further evidence to support no change in actual infection rates comes from testing for virus in wastewater, which also remained unchanged. ${ }^{4}$

Second, each week's surveillance population is not a true random sample, so extrapolating this estimate to the full student population could over- or undercount asymptomatic cases depending on the direction of bias (ie, healthy volunteer bias vs test avoidance by those with high-risk behaviors).

Finally, some students who were positive in surveillance testing may have been presymptomatic, rather than asymptomatic.

I In conclusion, we estimate that approximately $80 \%$ of students infected with SARS-
CoV-2 are asymptomatic. This is consistent with other studies in young adult populations. ${ }^{2}$

$$
\begin{array}{r}
\text { Mark H. Ebell, MD, MS } \\
\text { Cassie Chupp, MPH } \\
\text { Michelle Bentivegna, MPH } \\
\text { Department of Epidemiology and Biostatistics, College of } \\
\text { Public Health, University of Georgia, Athens } \\
\text { ebell@uga.edu } \\
\text { The authors reported no potential conflict of interest relevant } \\
\text { to this article. } \\
\text { doi: } 10.12788 / \mathrm{j} f \mathrm{fp} .0102
\end{array}
$$

\section{References}

1. Lee S, Kim T, Lee E, et al. Clinical course and molecular viral shedding among asymptomatic and symptomatic patients with SARS-CoV-2 infection in a community treatment center in the Republic of Korea [published online ahead of print August 6, 2020]. JAMA Intern Med. doi:10.1001/jamainternmed.2020.3862

2. Oran DP, Topol EJ. Prevalence of asymptomatic SARS-CoV-2 infection : a narrative review. Ann Intern Med. 2020;173:362-367.

3. UGA by the Numbers. University of Georgia Web site. www.uga edu/facts.php. Updated August 2020. Accessed October 20, 2020.

4. Lott M, Norfolk W, Robertson M, et al. Wastewater surveillance for SARS-CoV-2 in Athens, GA. COVID-19 Portal: Center for the Ecology of Infectious Diseases, University of Georgia Web site. www.covid19.uga.edu/wastewater-athens.html. Updated October 15, 2020. Accessed October 20, 2020.

\section{( Visit us @ mdedge.com/familymedicine}

